\title{
ACCESS TO ETHICS COMMITTEES IN BULGARIA - POSSIBILITY OR PROBABILITY
}

\author{
N. Gradinarova \\ Department of Medical Ethics and Law, Faculty of Public Health \\ Medical University - Sofia, Bulgaria
}

\begin{abstract}
The study of the legal framework regulating the activities of the Ethics Committees in the Member States of the European Union outlines several key factors forming the basis of the activity of the Ethics Committees. Compliance with the ethical principles of behaviour by physicians, patients, patients relatives, patient organizations and by the society as a whole requires professionals dealing with medical ethics and law to form, defend and bring to the knowledge and implementation an ethical code of behaviour of all participants in clinical trials as well as in the provision of medical services in general. The modern legal framework in Bulgaria, regulating the nature, functions and powers of the ethics committees, is complex and multi-layered, including both constitutional law and a number of acts at the law and bylaw level. Ethical committees set up in medical establishments aim to help physicians and other medical and non-medical specialists in the hospital, patients and their families coping with the ethical and legal dilemmas they face in everyday life. The results of a survey conducted among 149 medical specialists and 269 patients working and being treated in three different medical establishments in the country show that there is a low level of awareness of the types of ethical committees and their functions. $51 \%$ of the questioned medical specialists and $62.5 \%$ of the questioned patients replied that they were not aware when issues could be referred to the ethics committees in the country. The analysis of the regulation of the activities of ethics committees in the healthcare systems within the $E U$ and in the health system in Bulgaria shows that there is a need to optimize the activity of the ethics committees operating on the territory of the country.
\end{abstract}

Key words: Ethics committees, regulation, access, Bulgaria

Corresponding author: Chief Assistant Professor Neli Gradinarova, LLM, MPH, PhD, Faculty of Public Health, Medical University - Sofia, email: neli.p.gradinarova@gmail.com

\section{INTRODUCTION}

\section{International and European regulation of ethics committees}

T

he duty to protect human health is directly related to the work of ethics committees in medical establishments and to the confidentiality of patients' health status. Article 8 [1] of the Charter of Fundamental Rights of the EU [1] enshrines the right of every person to "protect his or her personal data". In particular, paragraph 2 of that article provides that such data "must be processed in good faith for specific purposes and on the basis of the consent of the person concerned or by virtue of another legitimate ground provided for by law. 
The codes of ethics adopted by various national medical associations, hospital associations and other professional organizations are largely compliant with a number of international documents. Among them are the World Medical Association (WMA) documents including a number of declarations, statements and the International Code of Medical Ethics.

In 1964, the World Medical Association adopted in Helsinki the Ethical Rules for Medical Research on Humans, which were subsequently developed and supplemented. The development of the Declaration aims to promote ethical principles, to provide guidance to physicians and other participants in scientific research on humans. In medical research, care related to human well-being should take precedence over the interests of science and society. The main goal of medical scientific research on humans is to improve procedures for prevention, diagnosis and treatment, and to establish the aetiology and pathogenesis of diseases.

The study of the legal framework regulating the activities of the ethics committees in the Member States of the European Union outlines several key factors forming the basis of the activity of the ethics committees. Compliance with the ethical principles of behaviour by physicians, patients, patients relatives, patient organizations and society as a whole requires specialists dealing with medical ethics and law to form, protect and bring to the knowledge and implementation an ethical code of behaviour of all participants in clinical trials as well as in the provision of medical services in general.

\section{National regulation of ethics committees in the Republic of Bulgaria}

The modern legal framework in Bulgaria regulating the nature, functions and powers of the ethics committees is complex and multi-layered, including both constitutional law and a number of legal acts transposing the relevant directives adopted within the EU as well as guidelines for conducting clinical trials.

The national legal framework regulating the structure and operation of the various types of ethical committees that can be created on the territory of the country contains both law and bylaw regulations.

The main place, among the many legislative acts at the law and bylaw level, is held by:

- Health Law - effective since 01.01.2005;

- Law on Medicinal Products in Human Medicine effective since 13.04.2007;

- Law on Medical Devices - effective since 12.06.2007;

- Law on Professional Organizations of Physicians and Dentists - effective since 01.01.2007;
- Ordinance No. 31 of 12 August 2007 laying down the rules for good clinical practice;

- Ordinance No. 2 of 05.02.2008 on the requirements for the collection, confirmation and provision of information on adverse drug reactions and on the content and form of emergency reports on adverse drug reactions and periodic safety reports;

- Ordinance No. 18 of 20 June 2005 on the criteria, indicators and methods for accreditation of medical establishments - effective since 16.07.2005;

- Code of professional ethics of the physicians in Bulgaria - issued by the Ministry of Health - Prom. SG. No. 79 of 29 September 2000 , amend. SG No. 85 of 28 September 2013;

- Rules of the Terms and Procedure of work of the Central Ethics Committee at the Council of Ministers under the Law on Medicinal Products in Human Medicine - adopted by CM Decree No. 239 of 28.09.2007, Prom. SG. No. 81 of 9 October 2007, amend. SG. No. 47 of 22 June 2012;

- Rules of the work of the Professional Ethics Committee of BMA - adopted on 19.06.2015 by the Professional Ethics Committee of BMA.

According to Art. 29, [2] of the Constitution of the Republic of Bulgaria [2], "no one may be subjected to medical, scientific or other trials without his/her voluntary written consent". Pursuant to Art. 17, [4] of the Law on Medical establishments [3], clinical trials shall be conducted in accordance with the Law on Medicinal Products in Human Medicine (LMPHM) [4]. In conducting the clinical trials, this regulatory act provides for the observance of the fundamental principles of human rights and dignity protection as established under the Helsinki Declaration according to the rules of Good Clinical Practice as required by Regulation (EC) 1901/2006 and according to the ethical principles.

There are also a number of codes of ethics that establish rules and principles in conducting clinical trials such as the Code of Professional Ethics, the Code of Ethics of the Bulgarian Association for Clinical Trials and codes of ethics of the research pharmaceutical industry and generic pharmaceutical manufacturers.

The legislative framework of clinical trials in Bulgaria, which has adopted and transposed European and international rules and standards in the planning and conduct of clinical trials, is of crucial importance for Bulgaria's participation in the conduct of multi-centre international clinical trials.

Ethical committees set up in medical establishments aim to help physicians and other medical and nonmedical specialists in the hospital, patients and their 
families cope with the ethical and legal dilemmas they face in everyday life. Professional ethics is also a value-normative theory of the behaviour of people in a profession. For the presentation of professional competence and responsibility in medical practice, committees of professional ethics at professional organizations around the world are helping. One of the most significant contributions of these committees is their involvement in the periodic updating of the codes of professional ethics. They analyse, explore, compare and systematize in a specific way the moral norms and values of a profession. At the core of professional ethics is the category of professional debt.

The work of the Ethics Committees, which are being established in the medical establishments in Bulgaria, is regulated by the Rules of the Structure and Activity of the Medical establishments and the Head of the Medical establishment can establish separate Rules of work for the ethics committee.

The Act setting out the functions and powers of the ethics committee specifies the application of the legal acts regulating the protection of the rights, the safety and the welfare of the patients, of the medical specialists in the medical establishment, as well as of the participants in the scientific research carried out within the medical establishment.

The regulated rules ensure that high standards of ethical conduct are respected by all persons involved in the medical-diagnostic process and in the overall medical practice, as well as the practice of the researchers and the research team members at each stage of scientific research conducted within the medical establishment.

The work of the Ethics Committees takes place in accordance with the UN Universal Declaration of Human Rights, the Helsinki World Medical Association Declaration on Ethical Principles in Biomedical Research, the Bioethics Convention, and all relevant legal instruments of the European Commission relating to ethics of scientific research. The Commission's work is also based on acts of domestic legislation such as the Health Law, the Ordinance No.14 of 2000 on the Terms and Procedure for Clinical Trials of Medicines on Humans and other documents in the field of ethics of scientific research and scientific publications.

Ethics committees are independent expert and advisory bodies for evaluation and giving positions on the ethical aspects of the provision of medical services as well as the ethical aspects of scientific research conducted in the medical establishment.

The subject of ethics expert assessment are the medical-biological, medical-clinical and medical-so- cial activities and research, and ethical committees within the medical establishments develop standard operating procedures, guidelines and forms for assessing the ethical aspects of the issues addressed to them.

The role of the ethics committees in the sustainable development of healthcare is to protect the patient and the institution - the autonomy, the right to help the patient. Ethics committees have the following main objectives: to encourage staff to share information with the patient; to develop standards by which to make decisions; to make decisions that, in certain cases, life-support systems should cease; and to make decisions at micro or macro level.

In addition to the listed and functioning structures concerning ethical behavioural norms in healthcare, there is a committee on these issues at the BMA. Its function is to resolve issues and dilemmas that arise when practising the medical profession. The Commission accepts and examines complaints from physicians about unfair competition or from citizens regarding the actions of a certain physician (as a legal basis, the observance of the Code of Professional Ethics [5] adopted at the XXXIII Extraordinary Meeting of BMA is accepted).

\section{Types of ethics committees in Bulgaria}

Ethics committees are set up to meet the needs of a more systematic and principled approach to medical-ethical dilemmas in decision-making in medical practice and to link the values of the society to the institution that takes care of the patients and treats them and in which cases there are ethical dilemmas.

Ethics committees in medical establishments have several key functions: educational - to train and assist medical staff in the importance and work with ethics committees and ethics codes, to help the better understanding of the medical staff on medical legal and bioethical issues, consultative - to advise and assist the patients, their families, the treating doctors and other health professionals to identify, formulate and solve ethical dilemmas, and rulemaking - to create different guides and instructions, to offer and recommend administrative measures and instructions on emerging medical-ethical problems.

The basic principles on which the Ethics Committees are created and function are: independence (to achieve independence and quality in decision-making, ethics committees must be structured and must have adopted certain standards), competence (to apply knowledge and experience, constantly raising the level of professional qualifications), pluralism (the ability to admit and respect many opinions, views or points of view on a given issue), transparency (ad- 
herence to strict principles, monitoring of the activity), interdisciplinary approach, dialogue (ability to communicate, gather more and accurate information).

\section{Types of ethics committees}

The legal framework establishes ethical committees of different types, structure and functions, including: Central Ethics Committee (CEC); Ethics committees in the medical establishments, according to the Law on Medicinal Products in Human Medicine; Ethics Committee of Scientific Research (ECSR); Ethics Committee of Scientific Research at the Medical University - Sofia (ECSRMUS); Ethics Committee of Scientific Research at the Medical University - Pleven; Ethics Committee of Scientific Research (ECSR) at the Medical University - Varna; Ethics Committee for Multi-Centre Trials (ECMT); Professional Ethics Committees of the Regional Colleges of the Bulgarian Medical Association (BMA) and the Bulgarian Dental Association (BgDA).

The purpose of this article is to study the legal framework at European and national level on the types of ethic committees that exist and operate on the territory of the Republic of Bulgaria, through a survey to verify the real awareness of the medical specialists and patients about the existing ethics committees in the country and to outline guidelines for a more effective future work of ethics committees.

\section{MATERIALS AND METHODS}

In order to verify the awareness of the medical specialists and patients in the Republic of Bulgaria about the existing ethics committees in the medical establishments in the country and the usefulness of their functioning, a survey was carried out among 149 medical specialists working in three medical establishments - Multiprofiled hospital for active treatment Doverie - Sofia , First Multifrofiled Hospital for active treatment - Sofia and Multiprofiled hospital for active treatment Dr. Dtanas Dafovski - Kardzhali and 269 patients treated in the same three above-mentioned medical establishments. The purpose of the survey is to identify the awareness of medical specialists and patients in the country and to determine the real access of medical specialists and patients to the ethics committee on the basis of the results obtained. The survey was conducted in the period 05.01.2017 - 05.02.2017. The choice of hospitals was random, two medical establishments for hospital care in Sofia, the capital of the Republic of Bulgaria (one private medical establishment and one state medical establishment), and one in the town of Kardzhali (stateowned medical establishment). The selection of the questioned medical specialists and patients was also random, which justifies the claiming of representativeness of the results.

\section{Results and discussion}

The medical specialists and patients were asked, "Do you know what type of ethics committees exist in Bulgaria?" Only $29.5 \%$ of the medical professionals and $17.8 \%$ of the patients are aware that ethical committees exist and function in the medical establishments. $12.1 \%$ of the questioned medical specialists and $8.2 \%$ of the questioned patients are informed that ethics committees for scientific research exist at the medical universities in the country. Only $9.4 \%$ of the medical specialists and $5.6 \%$ of the patients are the informed that there is an Ethics Committee for Scientific Research (ECSR) on the territory of the country. Only $6 \%$ of the questioned medical specialists and $1.5 \%$ of the questioned patients are aware of the existence of an Ethics Committee for multi-centre trial (Figure 1).

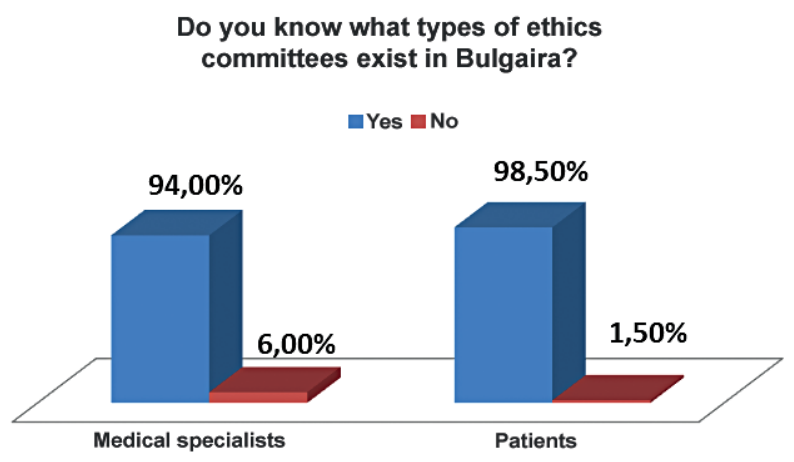

Fig. 1. Results from the survey. Question 1 - "Do you know what types of ethics committees exist in Bulgaria?"

Any specialist in the country who has successfully completed a higher education degree in medicine and wants to practice the acquired specialty of a physician is obliged to be a member of the respective BMA College. A Committee on Professional Ethics exists and functions at every regional college of the Bulgarian Medical Association. Only 25.5\% of the questioned medical specialists, all of whom are members of the BMA according to the law, are aware that a committee on professional ethics has been established in the college in which they are members. Only $9.7 \%$ of the patients questioned are aware of the existence of ethics committees with BMA, BgDA and the Bulgarian Association of Healthcare Professionals (BAHP).

When asked "Do you know when issues can be referred to the ethical committees", more than half of the medical professionals ( $51 \%$ of the questioned) 
have stated that they were not aware of when issues can be referred to the ethics committees. $62.5 \%$ of the patients questioned have no information when issued can be referred to the ethics committees in the country (Figure 2).

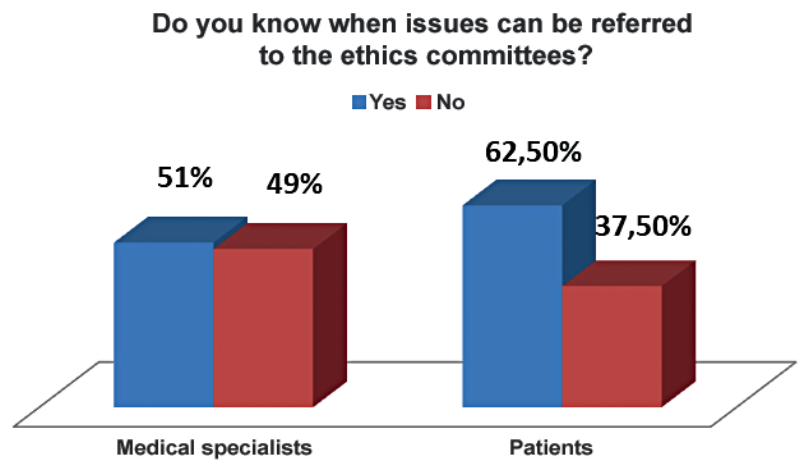

Fig. 2. Results from the survey. Question 2 - "Do you know when issues can be referred to the ethical committees"

Asked "Are you aware of the powers and responsibilities of ethics committees?" $23.5 \%$ of the medical professionals and $35.7 \%$ of the patients questioned have stated that they had no information on the powers and responsibilities of the ethics committees.

Asked: "Is there an ethics committee in the medical establishment in which you work / are treated?" $46 \%$ of the questioned medical specialists and $68.8 \%$ of the questioned patient have stated that they were not aware whether there was an ethics committee in the medical establishment in which they worked/were treated.

The analysis of the results of the questionnaire survey among the medical specialists and among the patients shows that there is a low level of awareness about the nature, role and functions of ethics committees operating on the territory of the country. In practice, the existence of ethics committees is very limited, and it remains for the most part in theory, depriving medical specialists and patients of the possibility of being active participants in healthcare. There is, in theory, any possibility that medical specialists and patients to get in contacts with the ethics committees in the country, but in reality they are deprived of this opportunity. The lack of knowledge on the part of medical specialists and patients of the types of ethical committees and their functions is a clear obstacle to their proper and complete functioning. Workshops, seminars and training modules for medical professionals and patients are needed.

\section{CONCLUSION}

The analysis of the regulation on the activities of ethics committees in the healthcare systems within the EU and in the healthcare system in Bulgaria shows that there is a need to optimize the activity of the ethics committees operating on the territory of the country.

Regular meetings should be organized with regard to the staff of the medical establishments in the country to discuss both general theoretical issues related to the ethics committee's work and practical aspects of everyday practice.

It is necessary to introduce information materials in the day-to-day service of patients in the medical establishments, which would facilitate the communication between the staff of the medical establishment and the patients and their relatives. This type of initiative would also have a preventive character in view of the issues raised before the ethics committee of the medical establishment. When the patient is aware of the possibilities available to him to resolve ethical conflicts, this would restrict the indiscriminate referral to the ethics committee, especially in cases where there is no factual and legal complexity, and yet it would give him access to the Ethics Committee in the cases provided by the medical establishment.

\section{REFERENCES}

1. Charter of Fundamental Rights of the European Union, 2012 I C 326/02.

2. Constitution of the Republic of Bulgaria, State Gazette No. 56/13. 07.1991.

3. Law on Medical Establishments, Prom. SG. No. 62 of 9 July 1999.

4. Law on Medicinal Products in Human Medicine, Prom. SG. no. 31 of 13 April 2007.

5. Code of professional ethics of physicians in Bulgaria - issued by the Ministry of Health - Prom. SG. No. 79 of 29 September, 2000, amend. SG 85 of 28 September 2013.

Received: March, 2019 - Revised: April, 2019

Accepted: June, 2019 